\title{
LAS “ABEJAS” FRENTE A LAS “ARAÑAS”: UN SECULAR DEBATE SOBRE EL FUTURO DEL LIBRO ANTIGUO
}

\author{
Nicolás Bas Martín* \\ Departamento de Historia de la Ciencia y Documentación. Universidad de Valencia.
}

Resumen: La irrupción de Internet en la Sociedad de la Información ha revolucionado de forma notoria los usos de lo escrito, de la cultura impresa. De esta manera, el acceso y difusión al libro antiguo, secularmente reducido a unos pocos privilegiados, se ha democratizado de forma notable gracias a la Red. Lo antiguo y lo nuevo han vuelto a convivir. Un debate que nos traslada a la Edad Moderna, cuando la República de las Letras, los actuales internautas, reflexionó sobre la autoridad de los antiguos y modernos. Han pasado muchos siglos desde entonces, y la vigencia del libro antiguo, pese a los cambios tecnológicos, sigue siendo la misma. Únicamente los soportes han cambiado, pues los mensajes, siguen siendo similares a los que encontramos durante el Antiguo Régimen Tipográfico. Una evidencia más de cómo la cohabitación se impone a la idea de la sustitución de unos medios por otros.

Palabras clave: Internet; libro antiguo; biblioteca digital; cartas; blogs.

Title: THE "BEES" VERSUS THE "SPIDERS": A SECULAR DEBATE ON THE FUTURE OF THE OLD BOOK.

Abstract: The advent of Internet in the Information Society noticeably has revolutionized the uses of writing, of print culture. Thus, access and dissemination to the ancient book, secularly reduced to a privileged few, has been democratized noticeably thanks to the Net. Old and new have returned to live with. A debate that takes us to the Modern age, when the Republic of Letters, the current Internet, reflected on the authority of ancient and modern. It has been many centuries since, and the life of the ancient book, despite the technological changes, remains the same. Only the media has changed, the messages remain similar to those found during the Old Typography Regime. Evidence of how cohabitation is imposed on the idea of substitution by other means.

Keywords: Internet; old books; digital library; letters; blogs.

\section{INTRODUCCIÓN}

Mientras escribo estas palabras soy consciente de que ya mañana habrán quedado desfasadas. No en vano, la obsolescencia de la información que viaja por Internet es tal que la actualización de contenidos supone una empresa cuanto menos utópica. Lo de hoy ya es antiguo frente al mañana, lo moderno, algo que no nos debe hacer caer en un maniqueísmo sin sentido. Más al contrario, mi objetivo será mostrar aquellas herramientas

*nicolas.bas@uv.es

Recibido: 13/07/2011; 2ª revisión: 24/11/2011; aceptado: 13/12/2011.

BAS MARTÍN, N. Las “abejas” frente a las “arañas”: un secular debate sobre el futuro del libro antiguo. Anales de Documentación, 2012, vol. 15, n 1. http://dx.doi.org/10.6018/analesdoc.15.1.132791. 
más útiles hasta la actualidad para el estudio de las bibliotecas y del libro antiguo en la Edad Moderna disponibles en la Red.

\section{LO NUEVO COMO AMENAZA DE LO ANTIGUO}

En 1831 el genial Víctor Hugo en su Notre-Dame de Paris, ponía en boca del archidiácono de la ilustre catedral Frollo, las palabras ceci tuera cela, la imprenta acabará con la arquitectura, con las catedrales. Una profecía que podemos aplicar al papel que las nuevas tecnologías tendrán sobre el libro, en este caso, antiguo. Recientemente, Umberto Eco en su libro Nadie acabará con los libros, ante la pregunta de qué salvaría de su casa en caso de incendio, respondía con rotundidad, mi USB con los cerca de treinta mil folios de mis últimos años de trabajo, y mi preciado incunable Viaje a Tierra Santa (1498) de Bernardo de Breidenbach, impreso para más inri en Zaragoza en las prensas de Pablo Hurus.

Han pasado casi dos siglos desde los presagios de Frollo y ni el libro ni las catedrales han desaparecido. Todo ello en un periodo en el que los nuevos medios de comunicación (radio, televisión, Internet), han hecho su aparición de forma notoria. Es por ello por lo que resulta más apropiado hablar de cohabitación más que de sustitución de unos medios por otros. Más al contrario, resulta que nunca como hasta ahora un medio, como ahora Internet, había hecho tanto por difundir el libro antiguo.

Desde la invención de la imprenta, y pese a su innegable labor de multiplicación de copias hasta ahora reducidas a los manuscritos, el acceso al libro impreso fue privilegio de unos pocos. Para los hombres y mujeres del siglo XVIII, por poner un ejemplo, la adquisición de los clásicos Elzevirios, Estiennes, Plantinos, Manucios, y no digamos de la Encyclopédie, nuestros libros antiguos actuales, requería de grandes esfuerzos económicos y no pocas gestiones. A partir del siglo XIX, se inicia una tímida democratización asociada a géneros más populares, como la prensa y la novela, adscrita sobre todo a la incipiente clase burguesa. Las clases populares hasta entonces únicamente tenían acceso a los llamados pliegos de cordel, comedias, romances, y literatura menor (panfletos, libelos, etc.). Para poder acceder al libro antiguo durante los siglos XV-XIX había que tener, por lo general, un estatus económico importante, y por supuesto unos niveles de alfabetización considerables.

El futuro como predijo MacLuhan en 1962 no se ha producido. La era de la electrónica no ha provocado la desaparición de la palabra escrita, del libro antiguo. Más bien éste ha encontrado en la Red un fiel aliado, que ha permitido lo que nunca hasta entonces se había producido en la historia del libro y la edición, la democratización del acceso a los libros. Salvando las distancias de la lamentable brecha digital que sigue separando al primer del llamado tercer mundo, que esperemos pronto se supere, la práctica totalidad de la humanidad, una de cada cuatro personas según los últimos datos, y en ritmo ascendente, pueden acceder a Internet. Ello nos lleva a entender la relación libro antiguo-Internet como de mutua reciprocidad. El primero conoce una difusión y accesibilidad nunca hasta 
ahora conocida; mientras que las nuevas tecnologías encuentran en el libro antiguo un mercado inabarcable. Circunstancia que no quita el que los nuevos medios electrónicos hayan generado una inicial turbación en la población que los vive, al igual que la imprenta generó en los hombres del siglo XV. Lo nuevo aparece así como una amenaza de lo antiguo. Dejemos hablar a Niccolò Perotti en una carta dirigida a Francesco Guarnerio en 1471.

«Estimado Francesco, últimamente no he cesado de alabar la época en la que vivimos debido al gran, incluso divino regalo que ha supuesto la nueva forma de escritura que recientemente nos ha llegado de Alemania. De hecho, he visto cómo un solo hombre imprimía en un mes lo que varias personas necesitarían años en escribir a mano... Esto me hizo concebir la esperanza de que dentro de poco tiempo dispondríamos de tal cantidad de libros que no existiría una sola obra que no pudiéramos conseguir por falta de medios o escasez de ejemplares... Pero ahora me doy cuenta -jay de mis pensamientos

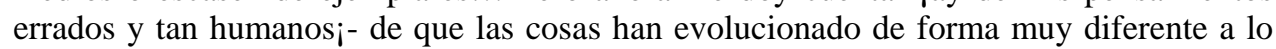
que imaginé. Porque ahora que todos son libres de imprimir lo que les venga en gana, con frecuencia se desprecia lo que tiene más valor y en su lugar se escribe, con el solo afán de entretener, lo que sería mejor olvidar o incluso borrar de los libros. Y cuando escriben algo que vale la pena, lo tergiversan y lo corrompen hasta el punto de que sería preferible que esos libros no existieran, antes que tener miles de ejemplares difundiendo falsedades por el mundo entero» ${ }^{1}$.

“Odio leer libros nuevos”, escribía el crítico inglés del setecientos, Willian Hazlitt, en clara alusión a la literatura moderna de su siglo, a su juicio de escasa calidad en relación al “aire puro y silencioso de la inmortalidad”, de los clásicos, los Froissart, Tucídides, Cervantes, o Guicciardini, entre otros (Hazlitt, 1999, p. 54-55). En esta misma línea se situaba Voltaire al afirmar que "yo me atengo a los libros antiguos, pues siempre me enseñan algo; de los nuevos aprendo muy poco”. Seguramente no son los libros nuevos, sino la abrumadora explosión de novedades literarias las que amenazan al libro actual, y con ello al libro antiguo (Steiner, 2006b, p. 41).

\section{LO ANTIGUO COMO AMENAZA DE LO NUEVO}

En otras ocasiones ocurre al revés, lo antiguo aparece como una amenaza de lo nuevo. Sirva como ejemplo la visita del escritor francés Mercier, que relata en su prohibidísimo L'An 2440 (1770) su visita a la Biblioteca Nacional de Francia. Allí espera encontrar miles de espléndidos libros como los que había en la Bibliothèque du roi en tiempos de Luis XV. Sin embargo, para su gran sorpresa, sólo encuentra una modesta sala con cuatro pequeñas estanterías. Mercier pregunta qué ha sucedido con el enorme número de libros que debía haberse acumulado desde el siglo XVIII, además de la ingente cantidad de libros que ya existía entonces.

«Los hemos quemado todos», le responde el bibliotecario: «50.000 diccionarios, 100.000 libros de poesía, 800.000 libros de derecho, 1.6 millones de libros de viajes y 
1.000 millones de novelas». Una comisión de sabios los leyó todos, eliminó los que contenían falsedades y mentiras, y redujo las existencias a lo estrictamente esencial: unas pocas verdades y unos pocos preceptos morales universales que caben perfectamente en las cuatro estanterías (Darnton, 2010, p. 56).

Lo antiguo frente a lo nuevo, lo nuevo frente a lo antiguo. Un dilema, o mejor dicho querella, que iba a ocupar los mejores espíritus europeos de los siglos XVII y XVIII. Por entonces, la Academia Francesa se convirtió en el campo de batalla en el que los llamados "antiguos" (Montaigne, Racine) libraron sus batallas intelectuales frente a los "modernos" (Fontenelle, Perrault). Precisamente una batalla entre estos dos bandos literarios fue el motivo de una de las sátiras más importantes de aquella época, obra de Jonathan Swift, el Relato completo y verdadero de la batalla que el pasado viernes libraron los libros antiguos y modernos en la biblioteca de Saint James (1697), más conocido como la Batalla de los libros. Los antiguos aparecen aquí representados como las “abejas”, laboriosas y sagaces; frente a las "arañas", los modernos, narcisistas y dogmáticos. Dos motivos alegóricos que le sirven al escritor irlandés para poner sobre la mesa, mejor sobre una biblioteca, el envite bélico de dos concepciones intelectuales contrapuestas.

Salvando las distancias, Internet se ha convertido en esa nueva academia o biblioteca virtual en la que las "abejas”, los nostálgicos del libro antiguo, vierten sus críticas contra los postmodernos, las “arañas” que ven en la Red una herramienta innegable de progreso.

Lo cierto es que las tecnologías cada día quedan más obsoletas, al tiempo que algunos rastros de lo antiguo (postales, cartas, diarios, librerías de barrio), ya son casi cosa del pasado. El gran dilema al que se enfrenta el libro antiguo es al de su difusión. La digitalización, a priori democrática, defensora de los derechos de autor, y dirigida al bien común, puede tornarse una empresa cuasi monopolística, y con fines comerciales, como está ocurriendo con el proyecto Google Book search, por otra parte muy cuestionado. Entre sus objeciones principales: a Google se le escapan libros; no recoge todos los libros de EEUU ni mucho menos los de otras geografías, ofreciendo una visión anglosajona del libro antiguo, que puede distorsionar la realidad, y que ha provocado recelos importantes del lado europeo, especialmente francés, a través del Director de la Biblliothèque Nationale de France, Jean-Nöel Jeanneney; vulnera en ocasiones los derechos de autor; contiene errores de digitalización; preocupa el deterioro de las copias; está en entredicho la relevancia de los ejemplares digitalizados, lo que haría necesaria la ayuda de un Bibliógrafo; y finalmente, notamos la ausencia de características intrínsecas del libro antiguo (encuadernación, papel).

Pese a estas reticencias, nunca como hasta ahora los libros antiguos habían estado tan presentes en los medios. Entre ellos en la prensa. Esta misma semana dos grandes noticias tenían que ver con esto que venimos hablando. Por un lado, la firma del acuerdo entre la British Library y Google para digitalizar parte de sus fondos; y por otro, la digitalización de la biblioteca del naturalista Darwin con sus miles de anotaciones, hasta ahora custodiadas en la Universidad de Cambridge. Ahora bien, en ocasiones la euforia 
tecnológica puede llegar a ensombrecer la naturaleza misma del proyecto, cómo considerar que agrupar los libros de Darwin en una biblioteca virtual asegura su conservación para las generaciones futuras. Como si los libros depositados desde 1908 por el hijo de Darwin en la prestigiosa Universidad inglesa hubieran estado sometidos a los infortunios. Afirmaciones más inciertas aún, las de la prensa, cuando se ignora la vulnerabilidad de los soportes digitales y su vida útil corta frente a la durabilidad de todos los impresos anteriores al siglo XIX. Considerar la digitalización como la única forma de conservación es poco acertado. Igualmente las digitalizaciones son siempre parciales y no deben inducir a confusión sobre la posibilidad de acceder al saber universal desde tu casa y sin pestañear. El referido proyecto de la British Library y Google tan solo digitalizará un $0.3 \%$ de lo que alberga la biblioteca inglesa.

\section{LA COHABITACIÓN ENTRE LAS “ABEJAS” Y LAS “ARAÑAS”}

Lejos de tendencias maniqueas, lo cierto, señala Robert Darnton, es que ni el papel ni las bibliotecas muestran señales de desaparecer, ni Internet consigue acometer con éxito una obsesión actual: la sensación de estar desbordados por la ingente cantidad de información disponible e indefensos ante el problema de cómo encontrar información útil y valiosa entre tantisima información efímera e inútil. Ante tales obstáculos la memoria, parafraseando al gran historiador de las ideas Todorov, se constituye como un remedio contra el mal. La memoria que nos traslada al espíritu altruista de la Ilustración de aunar ahora digitalización y democratización, huyendo de los objetivos meramente mercantiles, y buscando el beneficio de todos. Para ello, es necesario que el Estado intervenga evitando la creación de monopolios, anteponiendo el interés general a la rentabilidad comercial.

Y todo ello desde la premisa de que "el miedo a los bárbaros (Google, digitalización) nos puede convertir en bárbaros”. En clara alusión a cómo la oposición frontal a las nuevas tecnologías carece de sentido, al igual que comulgar sin ningún tipo de objeción a las mismas puede llevar a producir precisamente lo contrario de lo que queremos. En términos de visibilidad y dado que vivimos en un mundo globalizado, la digitalización permitirá difundir los fondos antiguos de las bibliotecas, y sobre todo ponerlos al alcance de los investigadores. El libro original tiende a quedar como pieza de museo, únicamente accesible a aquellos que deseen conocer aspectos formales del libro (encuadernación, grabados, papel). En este caso, la digitalización será sinónimo de conservación del original y difusión del fondo. Por su parte, una postura excesivamente proclive a lo tecnológico no debe hacernos olvidar que las copias digitalizadas son vulnerables al deterioro y al envejecimiento. Y no digamos los microfilms cuya perdurabilidad es muy corta y su lectura una auténtica tortura. Han sido tradicionalmente razones de espacio las que han llevado a los bibliotecarios a microfilmar y digitalizar, olvidando que el papel tiene una duración mayor, sobretodo si es anterior al siglo XIX.

De una manera u otra parece evidente que las bibliotecas con fondos antiguos acabarán siendo bibliotecas sin libros, megabibliotecas digitales, tipo Google, al estilo de la Biblioteca de Babel de Jorge Luis Borges. Instituciones en las que los libros se 
custodiaran como auténticas momias, encerradas en sarcófagos, depósitos, e inaccesibles a una gran mayoría. Pero hasta que eso ocurra, que esperemos tarde muchos años, nos deleitaremos con esas espléndidas bibliotecas forradas de libros antiguos, en los que uno intuye con cierto entusiasmo que en algunos de esos anaqueles encontrará una pieza pérdida, desconocida o única. Mientras tanto, y hasta que el libro antiguo pueda algún día convertirse en pieza de museo, las nuevas tecnologías cohabitaran con los libros.

Y en esta línea, la verdad es que la potencialidad de Internet es formidable. La Red puede muy bien conseguir que vuelvan a emerger libros antiguos sepultados en las estanterías más recónditas, por raras, peliagudas, o simplemente, por haber sido injustamente olvidadas, y ponerlas de nuevo en los circuitos de la lectura (Jeanneney, 2007, p. 45). Es precisamente el soporte, la pantalla, lo que ha cambiado radicalmente las cosas en quinientos años de libro antiguo. Pues, como veremos, muchos de los servicios que se ofrecen actualmente en Internet existían anteriormente, si bien en formato papel. Un testimonio más de cómo lo antiguo y lo moderno han convivido pacíficamente durante muchos siglos.

\section{BIBLIOTECAS Y LIBRO ANTIGUO EN LA RED: LA CONTINUACIÓN DE UNA TRADICIÓN}

Sin ser excluyentes, es evidente que hacer referencia a toda la información que sobre el libro y las bibliotecas en la Edad Moderna figura en Internet sería cuanto menos imposible. Un acercamiento que realicé hace algunos años ${ }^{2}$, muchos para la Red, si bien ahora, analizo desde otro punto de vista. Aquella aproximación más descriptiva se completa ahora con una visión más reflexiva, donde se constata la modernidad de lo antiguo, y la antigüedad de lo moderno. Y todo ello a partir de una serie de ámbitos temáticos en los que el libro antiguo se convierte en uno de sus protagonistas.

1) Correspondencia: las cartas son una de las fuentes históricas más importantes para el conocimiento de la historia de la edición. Al filo de las cartas durante el llamado Antiguo Régimen Tipográfico surgió un verdadero mercado del libro antiguo, en el que se comentaban ediciones, precios, autores, tiradas, etc. El libro y las cartas aparecen pues como dos realidades indisociables, una simbiosis biblio-epistolar, que en el caso que nos ocupa alcanzó su máxima expresión. En este sentido destacan proyectos como el Electronic Enlightenment $t^{3}$, que recoge los casi doscientos volúmenes de cartas de personajes clave como Voltaire, Rousseau, Franklin, y Jefferson, entre otros, accesibles desde la Red, con una única salvedad, requiere suscripción. En esta misma línea figura la edición electrónica de la correspondencia de Voltaire a través de la Voltaire Foundation ${ }^{4}$ de la Universidad de Oxford, que paulatinamente va incorporando la correspondencia de otros interesantes personajes del momento, como Pierre Bayle, Helvetius y Morellet, por citar algunos.

Ojalá algún día podamos tener en la red las más de 50.000 cartas de la STN estudiadas por R. Darnton; o las casi 30.000 del epistolario de Mayans, entre otras. En mi opinión, en 
ningún campo del libro antiguo la red tiene mayor utilidad que en éste de poner al servicio del investigador las miles de cartas que se conservan. Y especialmente en algunas épocas, como el siglo XVIII, en las que las cartas se constituyen en herramientas de trabajo fundamentales para reconstruir la red de corresponsales en el circuito del libro (impresores, libreros, intermediarios, colporteurs, routiers, etc.) que teñían toda Europa ${ }^{5}$.

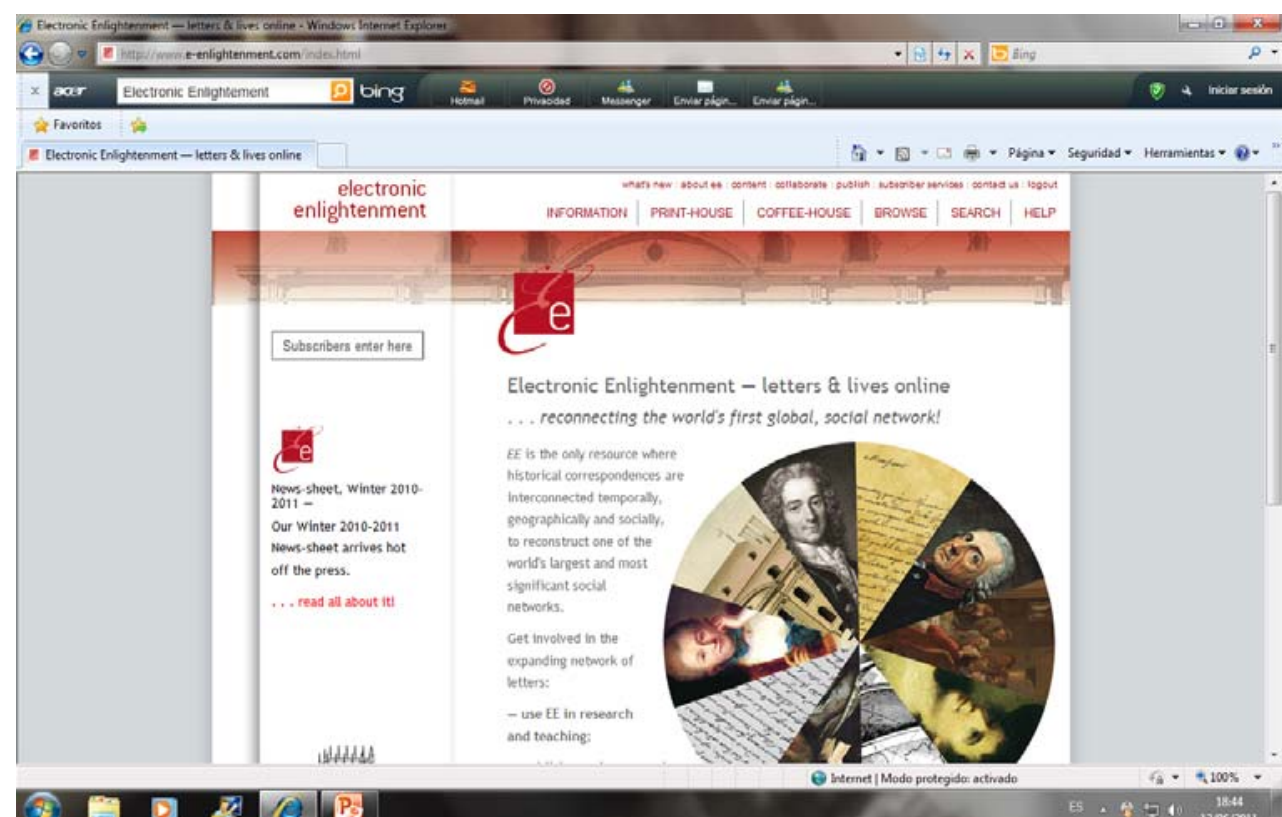

Figura 1. Portal Electronic Enlightenment.

¿Acaso los miles de correos electrónicos no constituyen ya una biblioteca de por si? Desde la Biblioteca de la Universidad de Harvard ya se trabaja en un proyecto para archivar los millones de correos electrónicos que se intercambian diariamente en la universidad ¿Es que esto no forma parte ya de la memoria? No serán estos correos fuentes para el estudio del libro antiguo por parte de los investigadores del siglo XXII o XXIII como lo son para nosotros las cartas del siglo XVIII. Sabemos de cientos de ediciones que no se llevaron a término gracias a la correspondencia, la llamada "biblioteca de los libros perdidos”, igual que proyectos actuales relacionados con el libro antiguo de los que sólo queda constancia a través de los emails.

Mientras redactaba estas palabras, tuve la ocasión de hallar una interesante correspondencia, Correspondance de quelques gens du monde sur les affaires du tems (1785-1795), mantenida en 1790 entre un ciudadano francés de nombre Velport con algunas nobles francesas, que ante el estallido revolucionario huyeron de París. Éstas, deseosas de saber lo que acontecía en la capital francesa, escribieron diversas cartas a Velport, que en una de ellas transcribo y traduzco textualmente señala: 
“Todo lo que actualmente puedo informarles, y remitirles, señora marquesa [Marquesa de Sommersé], es una corta noticia de algunos periódicos; únicamente os hago mención de cuarenta por este correo, en la próxima espero ser menos lacónico”.

\section{( I8)}

Te nouvel ordre de chofes. C'eft un jeane homme fort inftruit, non pas de l'hiftoire, de l'économie politique, des intérêts de fa Patrie; il a négligé ces bagatelles; mais il connoît nos thêâtres, nos modes, nos femmes, nos plaifirs dans une grande perfection; il danfe comme Veftris, monte comme Aflley, chante comme Martin, \& prétend que cette efpèce de talens réalife plus de bonheur que les calculs de M. Necker, que l'éloquence de'M. de Mirabeau \& que les connoiffances de M. Dupont. Si je raifonne, il bâille; fi j'infifte, il foupçonne que je radote; il me parle de mes préjugés gothiques, \& m'infinue que l'experience n'eft que la trifte routinę. Le ton décidé dont il me parle finit par m'en imporer; je le plains \& ine tais, jufqu'à ce que la raifon plus heureufe que moi lui faffe aimer fon langage.

Tout ce qui je puis aujourd'hui, c'eft de vous adreffer, Madame la Marquife, une courte notice de quelques Journaux; je ne vous en cite que quarante par ce Courier, dans la fuite je ferai moins laconique.

$x^{\circ}$. Le Journal de Paris, ne donne plus que le récit de ce qui fe.paffe à l'Affemblée Nationale, Cet article eft rédigé par $\mathbf{M}$. Garat, l'un des Députés. Il mêle un peu d'ef*

Figura 2. Correspondance de quelques gens du monde sur les affaires du temps (1785-1795).

Nada más y nada menos que un panorama de los cuarenta principales periódicos parisinos nos ofrecen estas cartas, que se detienen además en aspectos relativos al contenido y autores de los mismos. Una fuente de enorme relevancia para estudiar nuestros libros antiguos, y que sus contemporáneos, como ahora nosotros con los emails, no apreciaron en su justa medida.

2) Novedades sobre el libro antiguo: gracias a Internet es posible conocer las últimas novedades en el mundo del libro antiguo. Especialmente a través de blogs, elaborados por 
personas o instituciones muy vinculadas al libro antiguo, bibliófilos ${ }^{6}$ o profesores universitarios especialistas en la materia. De esta manera se nos informa puntualmente de congresos, seminarios, mesas redondas, publicaciones, etc. Todos ellos a su vez nos redireccionan a otros blogs o páginas similares, con lo cual entramos en un bucle que en ocasiones nos puede saturar de información. La mayoría de ellos nos permiten hacernos miembros y con ello recibir puntual información de lo que va apareciendo en el blog. En el ámbito europeo me gustaría destacar el portal Histoire du livre del profesor Frédéric Barbier del ENS (École Normale Superieure de París) que puntualmente nos informa de los acontecimientos más importantes relacionados con la historia del libro; y en el caso español, el portal de Grafosfera, desarrollado por el Seminario Interdisciplinar de Estudios sobre Cultura Escrita (SIECE).

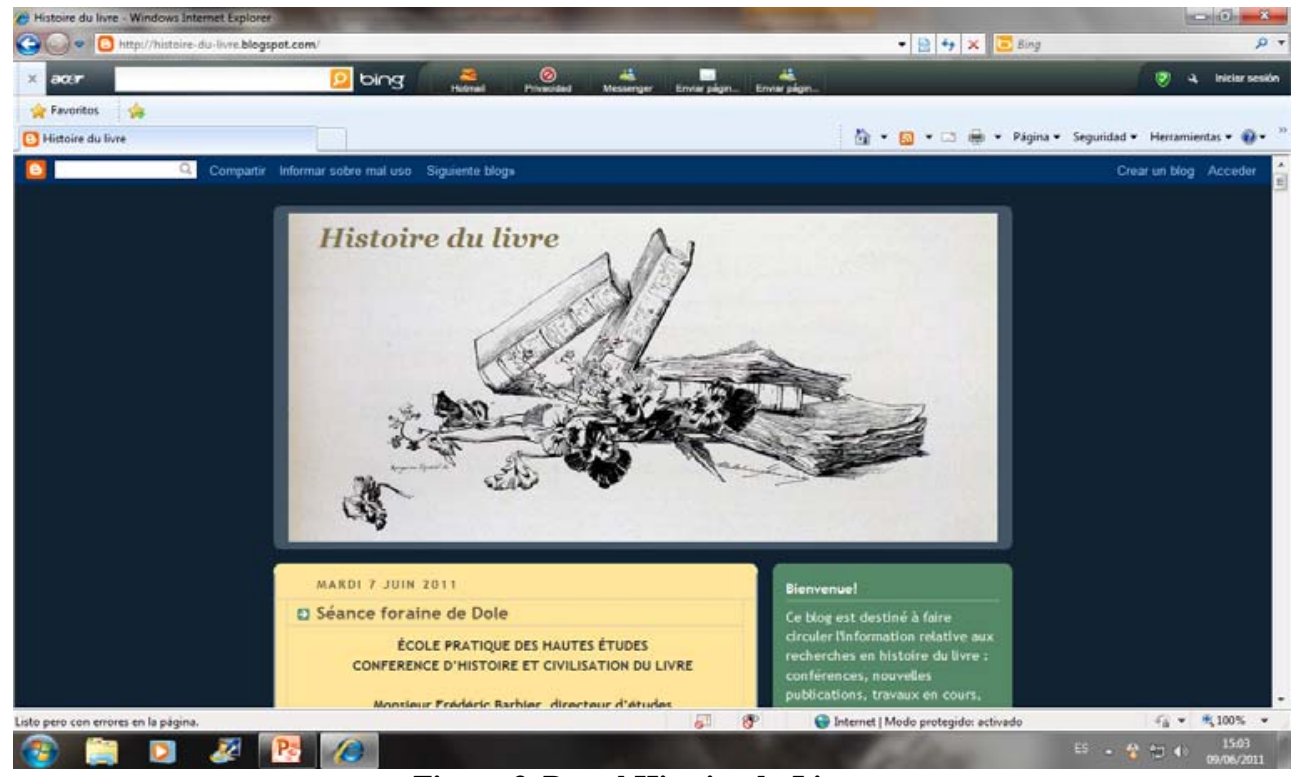

Figura 3. Portal Histoire du Livre.

Una vez más, la difusión de novedades sobre el libro antiguo no es algo actual, sino que viene de más atrás. Por entonces, durante la Edad Moderna, los periódicos tuvieron el eco del que actualmente goza Internet. Entonces los internautas se llamaban la "república de las letras”, el soporte era el papel, y tan sólo unos pocos privilegiados podían leer, sensu estricto, lo que allí se decía. Y por supuesto, la actualización de los contenidos estaba a años luz de la Red actual. Sirva como ejemplo el periódico Annales Typographiques (París, 1758-1763), que en su número del año 1758, recoge ya varias de las preocupaciones de la actual Sociedad de la Información. Así, hace referencia a la "masse totale des connoissances en augmente", lo que hace necesario: 
"Il seroit donc très-utile de présenter chaque année au monde savant tous les livres imprimés en Europe pendant le cours de l' année précédente”.

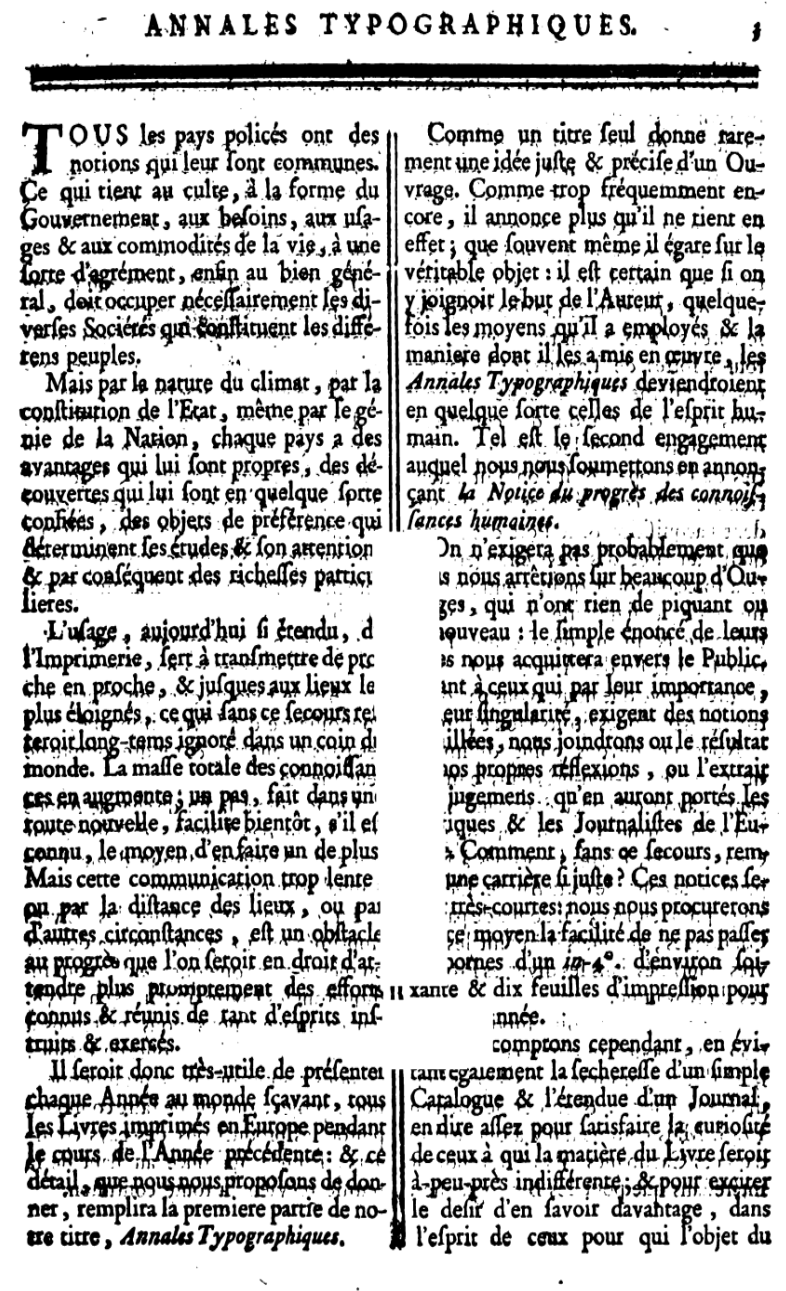

Figura 4. Annales Typographiques (1758-1763).

El término de "moderno" hacía referencia pues a lo publicado el año anterior al año en curso. Anterior a esta fecha ya se consideraba "antiguo" o desfasado. En esta misma línea figuran las Nouvelles de la République des lettres et des arts (París, 1779-1788), en las que se da noticia de todas las novedades literarias en una sección llamada "Livres nouveaux", similar a las novedades editoriales que encontramos en nuestros actuales blogs. 
8

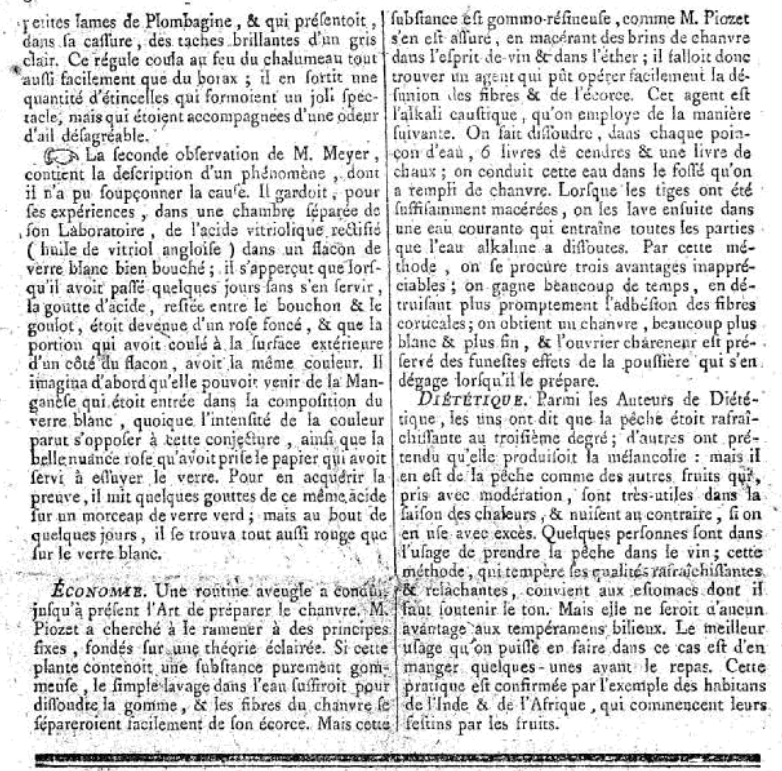

LIVRES: NOUVEAUX

Coffumes civils actuels de tons les Peuples connus, dédiés â M. le Maréchal de Caftries, MiAiftre \& Secrétaire d'Etat, ayant le département de la Marime; par M. Grafet de Suint-Sauveur,

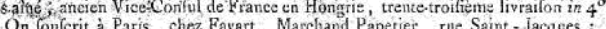

On lonlcrit a Paris, chez Favart, Marchand Papetier, , rue Saint - Jacques ; is lourrage fo

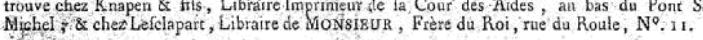

- Delaffement de l'homme fenfible, par M. de Anniaud, tome IV, quatrième partie in-12. A Paris, chez Buiflon, rae des Poitevins, N9, 13.

A PARIS, de l'Imprimerie de CAIL L E AU, rue Galaide. $\mathrm{N}^{\circ} .6_{4}$

Figura 5. Nouvelles de la République des lettres et des arts (1779-1788).

3) Mercado del libro: cualquier interesado en la historia del libro y de las bibliotecas durante la Edad Moderna deberá cotejar, bien como comprador o como investigador, los portales dedicados a librerías anticuarias, casas de subastas y ferias y salones. De hecho los servicios más demandados actualmente en Internet tienen que ver con compraventas online. La utilidad de este servicio radica en acercar los libros antiguos a aquellos que viven lejos de librerías anticuarias. La inmediatez y velocidad de venta es innegable, permitiendo hacer comparaciones de precios. Es el cliente el que selecciona al librero y no al revés, lo que desagrada a los libreros.

Además, y por lo general, se venden libros viejos no antiguos, descatalogados o imposibles de encontrar en librerías de nuevo. La realidad social de los usuarios de estos servicios online así lo demuestra, siendo mayoritariamente universitarios y profesionales jóvenes (Remírez de Esparza, 2008, p. 55). 


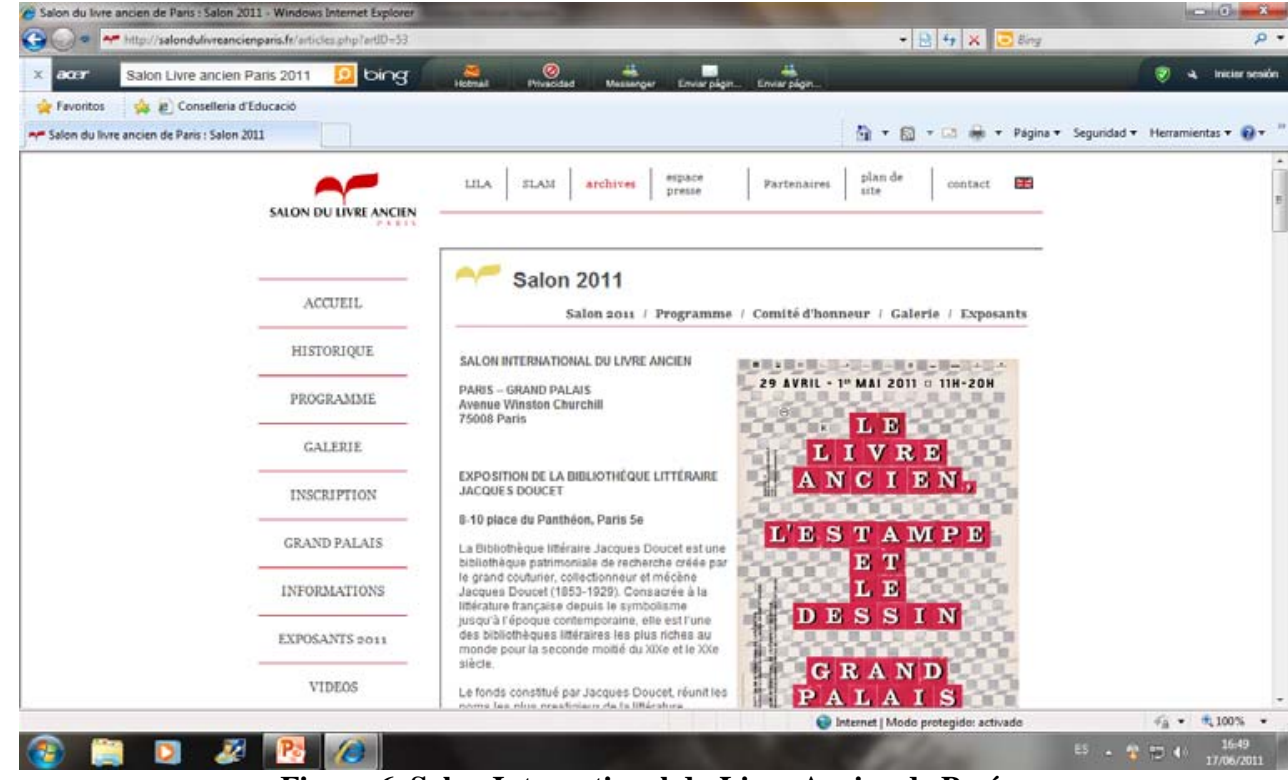

Figura 6. Salon International du Livre Ancien de París.

Una comodidad que lleva implícito algunos riesgos: imposibilidad física de cotejar el ejemplar; descripciones bibliográficas incompletas o erróneas; estado de conservación dudoso; pago por adelantado; o garantías del lugar de consulta (Díaz-Maroto, 2009, p. 304). No en vano en los últimos años el intrusismo ha aumentado de forma considerable. Por todo ello el olfato del comprador será determinante, pues se pierden elementos clave a la hora de concretar el precio de un ejemplar, como la apariencia, forma de hablar y conocimientos sobre libro antiguo de un comprador, ahora virtual.

Por ello algunos consejos clave para todos aquellos que se acerquen a este mundo son: examinar la rareza y condiciones del ejemplar, consultando repertorios bibliográficos; consultar otras fuentes (casas de subastas, librerías, bibliografías); no fiarse de las descripciones bibliográficas, cotejar el ejemplar o llamar a la subasta o librería en cuestión; si es una subasta, comprobar que el precio de salida se corresponde con la calidad del ejemplar; y si es una subasta virtual, caso de Romantic Agony, la pericia del comprador, el que logre fijar el último precio, será fundamental.

Contamos además con herramientas muy potentes como los metabuscadores o bancos de datos de librerías, tipo libroantiguo.com, o Livre-rare-book, así como conjuntos de bancos de datos, que contienen el fondo de miles de librerías, caso de Bookfinder. Todo ello ha hecho que Internet halla democratizado el acceso a los libros antiguos, hasta ahora limitados a aquellos privilegiados que recibían unos catálogos en ocasiones costosos, en especial si venían del extranjero. 
Dada la volatilidad del mercado, el fondo de armario de cualquier comprador e investigador sobre libro antiguo deberá estar formado por: repertorios bibliográficos, bibliografías de incunables y libros antiguos, tipobibliografías, topobibliografías, bibliografías especializadas, catálogos colectivos, catálogos de librerías anticuarias y subastas, y recopilaciones de libros tasados, como el libro El mercado del libro antiguo español. Una guía de precios, publicado por Ollero \& Ramos, y que recoge los ejemplares anunciados en venta desde 1988 hasta 1998, o el proyecto del Anuario Bibliográfico ANUBI, que lamentablemente se extinguió en el año 2002.

De nuevo, el formato tampoco nos sorprende por su novedad, pues a lo largo de la Edad Moderna las ventas de libros, vente aux enchères, fueron una costumbre en el mercado del libro. Especialmente en Francia tras la revolución, en la que los bienes eclesiásticos y de la nobleza inundaron el país de libros antiguos. De esta manera, los catálogos de bibliotecas privadas son una fuente indiscutible para estudiar los libros antiguos, pues en ellos hallamos obras no sólo contemporáneas, antiguas para nosotros, sino antiguas para sus propietarios. Como ejemplo la biblioteca del cardenal del siglo XVIII, Loménie de Brienne, donde es posible encontrar abundantes obras del siglo XVI, en especial de teología.

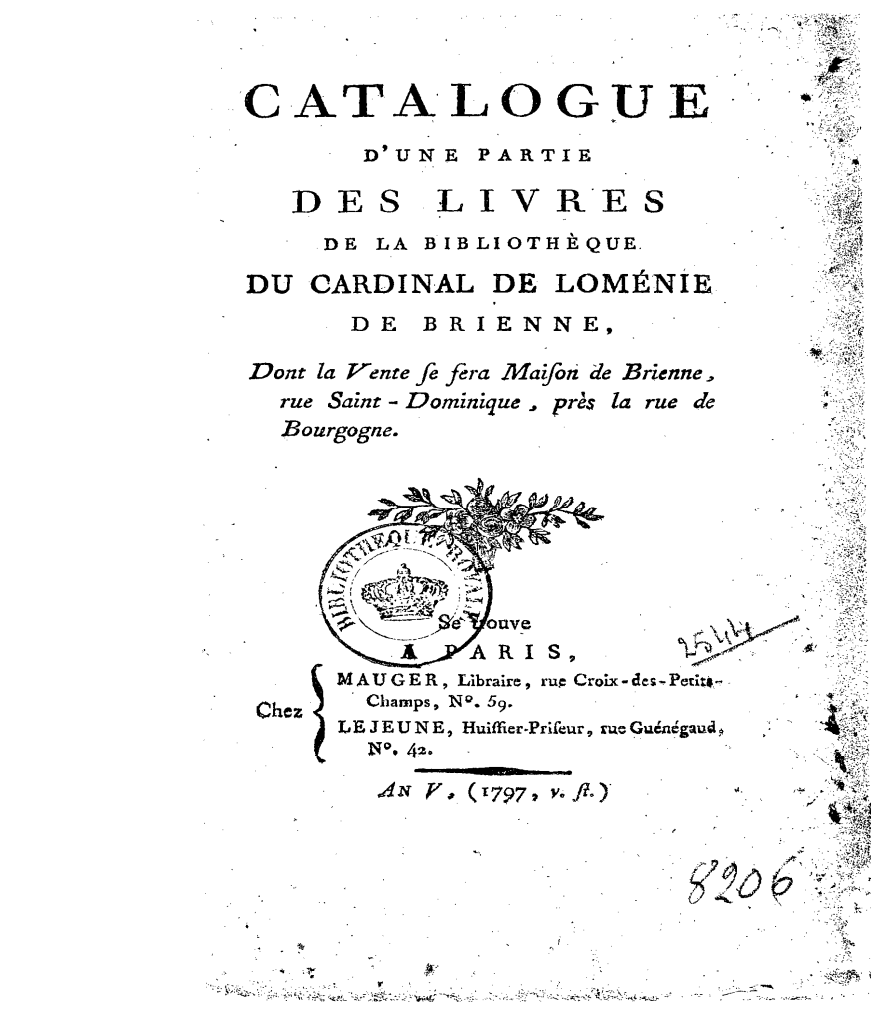

Figura 7. Catalogue des livres de la bibliothèque de Loménie de Brienne (1797). 
4) Catálogos colectivos: son otras de las herramientas básicas para localizar los fondos antiguos de las diferentes bibliotecas. Agrupan a diversas bibliotecas con fondo antiguo, y entre sus ventajas figura: permite la consulta simultánea de diversas colecciones de libros; y simplifican el proceso de consulta. Algunos de sus inconvenientes son que, en la actualidad, la gran mayoría siguen siendo incompletos, necesitan actualizarse y eliminar duplicados. Sería imposible enumerarlos todos, razón por la que citamos únicamente el Karlsruhe Virtual Catalog ${ }^{7}$, que recoge los más importantes a nivel europeo y americano.

Tampoco es una novedad del siglo XXI. Desde la Edad Moderna existen catálogos colectivos de libros antiguos, donde los curiosos e interesados por el libro antiguo podían conocer la localización exacta de los ejemplares. Entre ellos he seleccionado las bibliografías especializadas, concretamente la Bibliotheca botánica (1771-1772), la anatomica, la chrirurgica, y la de medicinae practicae del médico suizo Albert von Haller, donde se indica la localización de los manuscritos y códices en bibliotecas europeas.

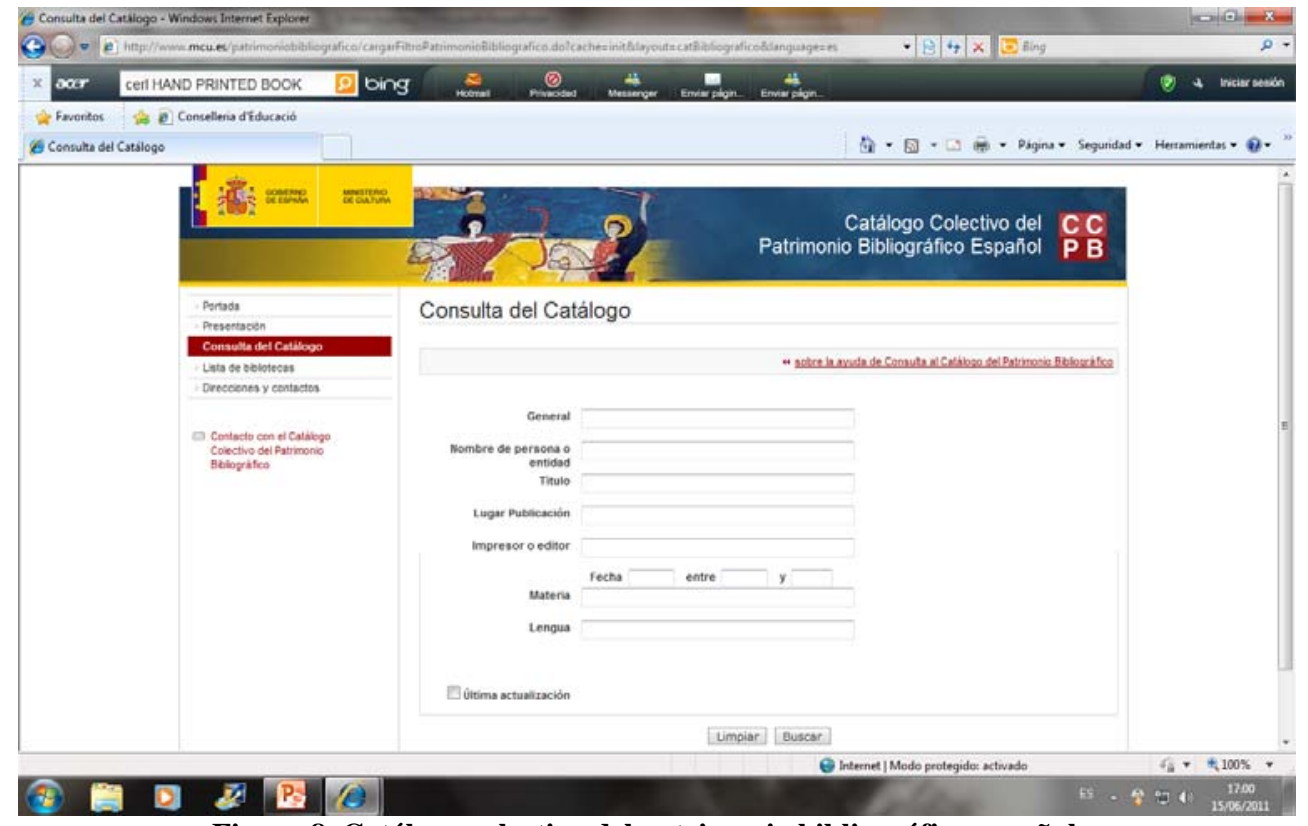

Figura 8. Catálogo colectivo del patrimonio bibliográfico español.

5) Bibliotecas digitales: es evidente que cualquier biblioteca que se precie actualmente debe tener cuanto menos iniciado un proyecto de digitalización de sus fondos, en especial antiguos. El problema principal radicará en establecer las pautas a seguir y los objetivos de la misma. No sirve digitalizar por digitalizar sino que se tienen que fijar criterios claros relativos a derechos de autor, conservación y preservación de las copias, y espectro cronológico y literario que se va a digitalizar, entre otros aspectos. 
Elementos que en nada disminuyen la importancia de lo digital y de la imagen en las bibliotecas actuales. Sirva como ejemplo la François Mitterrand de París que cuenta con tres departamentos principales: una mediateca, una fonoteca y una iconoteca. Por el contrario, el libro antiguo brilla por su ausencia, sepultado en los depósitos y únicamente consultable en molestos lectores de microfilm. La Red, la cultura digital, se constituye así en la Biblioteca universalis de Leibniz: una biblioteca ilimitada frente a los límites de la cultura analógica (Steiner, 2006, p. 65).

Es imposible mostrar todos los proyectos de digitalización, por lo que me detendré únicamente en aquellos más relevantes, en especial en el referente europeo, Europeana. En todos ellos hay una característica común, y es que dentro de su concepción de universalidad, recogen no sólo libros sino manuscritos, grabados, dibujos, carteles, mapas, partituras, etc.

El proyecto que mejor representa actualmente el ideal clásico de biblioteca universal es Europeana, que recoge el espíritu del afamado bibliógrafo suizo Conrad Gesner que en su Bibliotheca universalis (1545-1555) dio a conocer una biblioteca universal, tanto impresa como manuscrita. 5.000 autores y 16.000 títulos hicieron de su obra un referente bibliográfico en una Europa bastante convulsa. Precisamente una de las mayores preocupaciones de Gesner en su momento, como lo es ahora, era como organizar el caos informativo en el que vivía. Tan solo una persona se le adelantó, Johann Tritheim que en 1495 publicó en Maguncia el Catalogus illustrium virorum germaniae. Contemporáneas a la obra de Gesner figuraban la obra de John Bale, Illustrium maioris britanniae scriptorum (1548), y la Libraria de Anton Francesco Doni (1550). Ninguna de ellas tenía la concepción universal de la obra de Gesner, limitadas a la nacionalidad de sus autores o en el caso de Doni a la lengua italiana. La única objeción a la universalidad de Gesner fue su concepción lingüística, que quedó reducida al latín, griego y hebreo. A partir de entonces el calificativo universal pasó a ser denominador común de un número importante de obras y también periódicos, como la Bibliothèque universelle et historique (1686-1693) del teólogo suizo, Jean Le Clerc. 


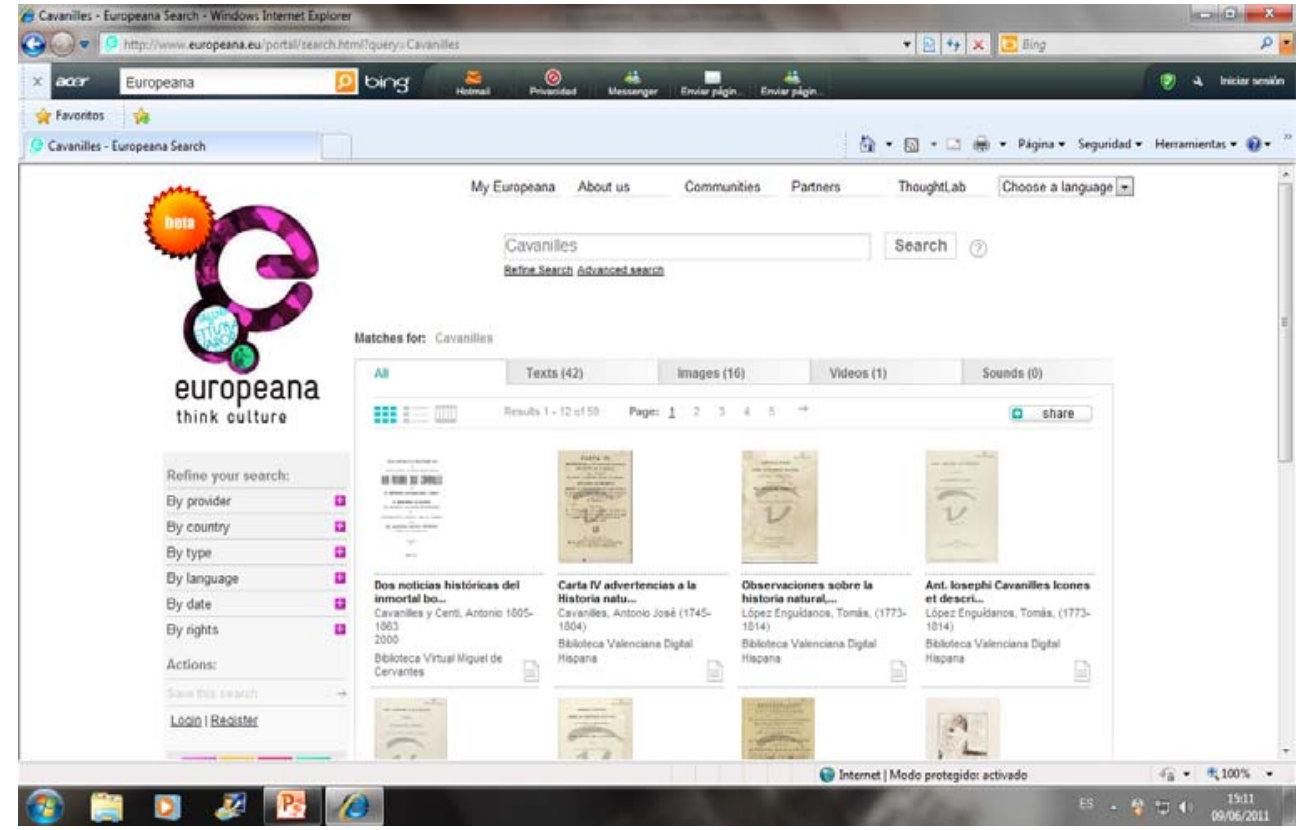

Figura 9. Biblioteca digital Europeana.

Una biblioteca sin fronteras, calificó Roger Chartier al proyecto de Gesner. Un proyecto de recuperar la ansiada Biblioteca de Alejandría recopilando todos los conocimientos universales, y que alcanzará su concreción en el proyecto de Otlet y Lafontaine de creación de la Oficina Internacional de Bibliografía (OIB). Lejos de alejarnos del modelo propuesto por Gesner, la transmisión electrónica de los textos, señala Chartier, hace posible la idea de la biblioteca universal:

"Entendiendo por esto que, si cada uno de los textos escritos o impresos del patrimonio textual es transformado en un texto electrónico, no hay razón por la cual no se pueda proponer una universal disponibilidad del patrimonio textual a través de la transmisión electrónica. La biblioteca, que abarca todos los textos escritos y todos los nuevos textos que se escriben, se transforma en una realidad virtual debido a que la diferencia fundamental entre el lugar del texto y el lugar del lector puede reducirse por completo con esta conversión electrónica de todo el patrimonio textual",

Nunca hasta ahora habíamos estado más cerca de la Biblioteca universal de Gesner. El sueño de la biblioteca universal parece hoy más cercano a hacerse realidad que nunca antes, incluso más que en la Alejandria de los Ptolomeos. El proyecto Europeana echa la vista atrás, a la historia, para hacer de los libros antiguos una de las primeras iniciativas supranacionales del antiguo G-7, uno de los once proyectos piloto para el desarrollo de la información global, ahora dirigidos por la Comisión Europea. El objetivo, facilitar el acceso al conocimiento e información que custodian 95.000 bibliotecas de la Unión 
Europea. "Instituciones de la memoria” que conforman La Idea de Europa de George Steiner, en la que los cafés, y añadimos las bibliotecas y librerías, conforman la esencia de un continente que atraviesa actualmente una crisis de valores. Al igual que la Biblioteca de Alejandria en su momento, crisol de la tradición cultural egipcia, helénica y latina, en la encrucijada entre Oriente y Occidente, la biblioteca digital Europeana se configura como el símbolo de un espacio único europeo de información, un encuentro de sinergias culturales.

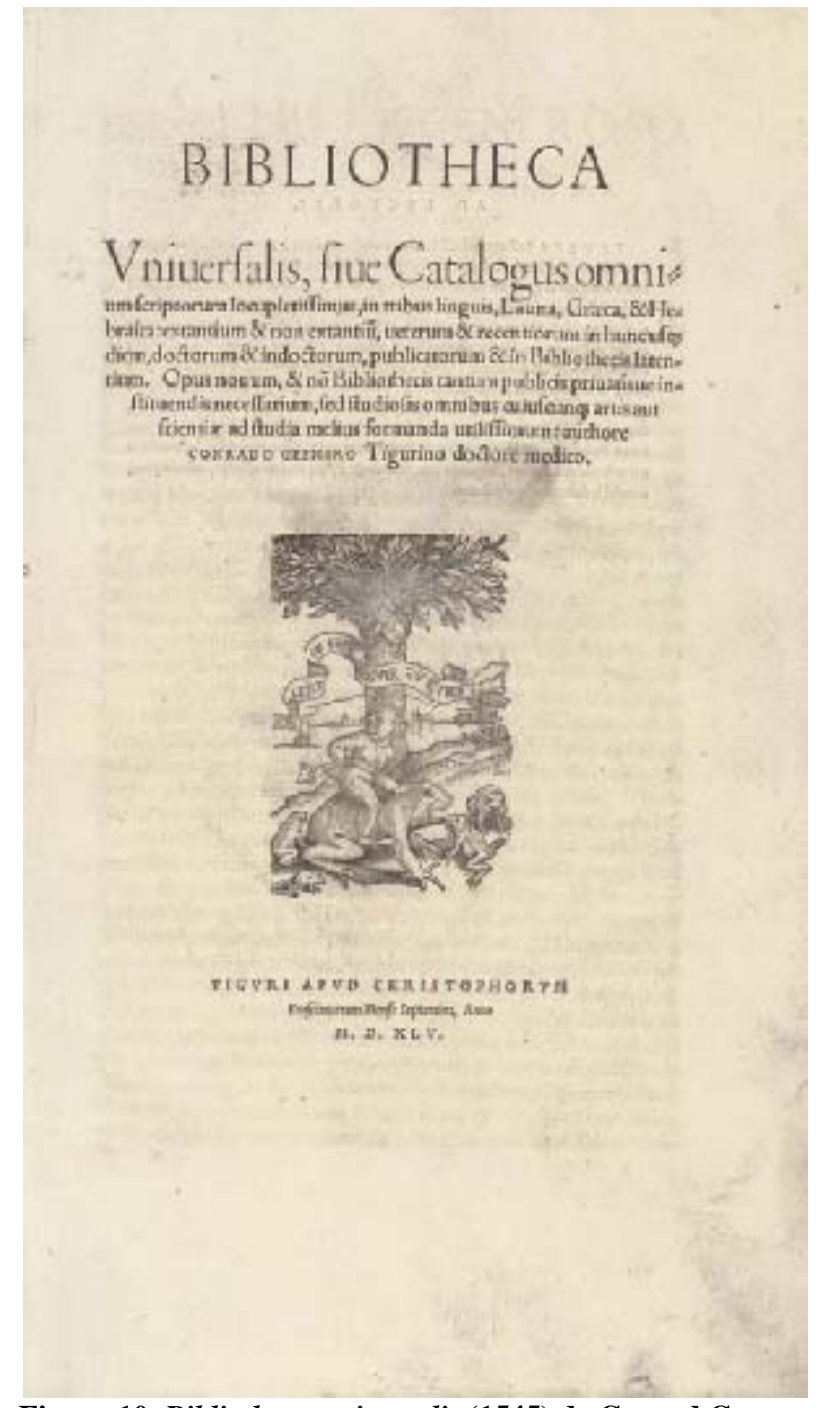

Figura 10. Bibliotheca universalis (1545) de Conrad Gesner. 
En la conferencia pronunciada en la inauguración de la IFLA en 1935, Ortega y Gasset señalaba que el concepto de "biblioteca moderna" surgió hacia 1850 cuando la sociedad satisfizo la necesidad de contar con libros y se generó la necesidad de buscar lectores. De forma análoga podríamos decir que el concepto de "biblioteca moderna", del siglo XXI, surgió cuando la sociedad satisfizo su ansia de información y generó la necesidad de buscar conocimiento. En ambos casos, el estado asumió la responsabilidad de satisfacer las necesidades sociales, entonces, a mitad del siglo XIX, creando bibliotecas para los lectores, y ahora, a principios del siglo XXI, facilitando el acceso a la información y al conocimiento a todos los ciudadanos a través de proyectos como ahora Europeana (Méndez Rodríguez, 2009, p. 42).

Al igual que en el siglo XVIII en el que la Encyclopédie se convirtió en el emblema de la época, en la biblioteca universal del momento, Internet, puede revivir el espíritu de la Ilustración, siempre y cuando los intereses públicos se antepongan a los privados. Los propios filósofos del siglo XVIII, como Voltaire y Diderot, consideraron los monopolios y privilegios, caso del Gremio de libreros de París, como el principal obstáculo a la difusión del saber. En este sentido, proyectos como ahora la digitalización de libros deberán velar por el respeto a los autores, editores y en último lugar lectores. Cuando se anteponen los intereses mercantiles a los públicos se producen frustraciones como la Encyclopédie Méthodique de Panckoucke o las polémicas que suscita la actual digitalización llevada a cabo por la empresa Google.

Entre los proyectos europeos de bibliotecas digitales más importantes destacan el Gallica francés, el Eighteenth century collections online, bajo suscripción, que recoge cerca de doscientas mil obras impresas inglesas durante el siglo XVIII, tanto fuera como dentro del Reino Unido; la Biblioteca digital hispánica de la Biblioteca nacional española, la Biblioteca digital Dioscórides de la Universidad complutense, y la BIVALDI de la Biblioteca valenciana, entre otras.

A las bibliotecas digitales se añaden otros recursos accesibles desde la Red, pero de menor relevancia, caso de los repositorios, de los que existen pocos dedicados al mundo del libro antiguo. Uno de los más importantes es el elaborado por la Universidad de Idaho, Repositories of primary sources, que ofrece la posibilidad de acceder a más de cinco mil páginas web dedicadas a los manuscritos y libros raros. Un servicio que ha quedado un tanto obsoleto tras la aparición de los blogs son las listas de distribución, que a través de servicios de alerta informan de novedades en un campo determinado, en este caso el libro antiguo. En lengua castellana destaca IWETEL a través de la RedIRIS, y en lengua inglesa el H-HistBibl.

En esta misma línea de servicios un tanto desfasados o meramente informativos figuran las asociaciones, especialmente numerosas en la tradición francesa y anglosajona, donde la bibliografía ha gozado de mayor predicamento. Entre las asociaciones y sociedades bibliográficas destaca The bibliographical society de Londres, la más antigua de Europa, que edita la célebre revista The library. También los museos, siendo muy 
recomendables todos aquellos, caso del de Lyon, que tienen asociado al museo un Instituto de historia del libro que celebra anualmente cursos, a cargo de profesionales cualificados, que compaginan las enseñanzas teóricas, con la asistencia a las colecciones museográficas.

A continuación existen numerosos portales que podíamos denominar de "Generalidades sobre libro antiguo”, que abordan asuntos puntuales sobre el libro antiguo, y que forman una especie de "cajón de sastre”, a veces sin orden ni concierto, que pueden desanimar al interesado. Aquí podemos encontrar páginas dedicadas a libros raros; información sobre aspectos materiales del libro antiguo (marcas de impresor, tipografías, filigranas); buscadores de bibliografía sobre historia del libro y de la imprenta, algunos de ellos desfasados; portales dedicados a recoger los manuales de tipografía publicados entre los siglos XVI-XVIII; o otras páginas más interesantes, y en especial para el tema que nos ocupa, como las dedicadas a ventas de bibliotecas de los siglos XVI-XVIII conservadas en bibliotecas parisinas ${ }^{9}$, editada por l'École des Chartes. Fuentes todas ellas indispensables para reconstruir el mundo de las bibliotecas privadas, de las lecturas y lectores durante la Edad Moderna.

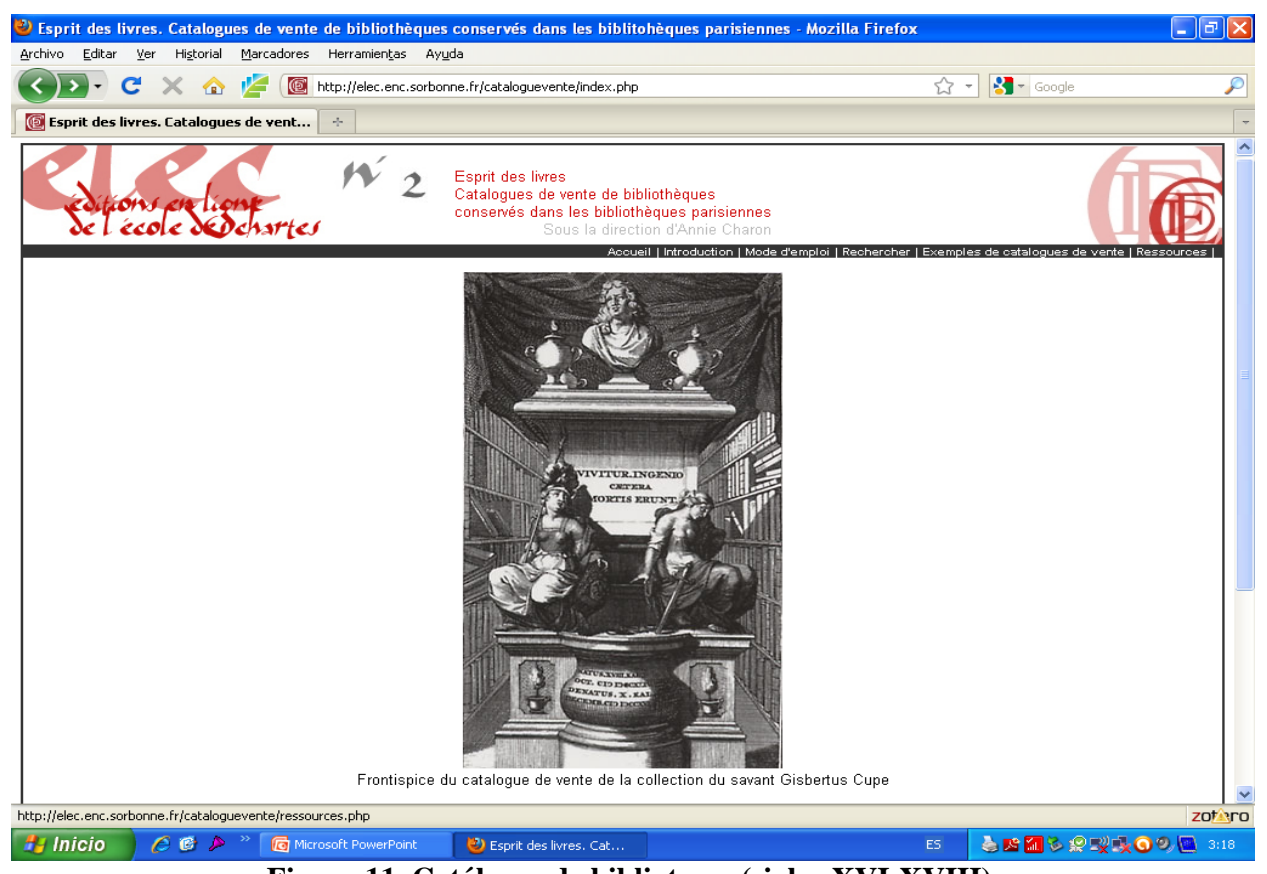

Figura 11. Catálogos de bibliotecas (siglos XVI-XVIII).

Seguramente los retos más importantes en la consulta online de libros antiguos en la Red vengan de la mano de las publicaciones periódicas y de la llamada Web social. Respecto a las primeras, las revistas, lamentablemente son muy pocas las que quedan en 
España, y de ellas prácticamente ninguna tiene acceso online, al igual que en el resto de Europa, donde únicamente es posible acceder a los resúmenes o sumarios. En una sociedad en la que se está trabajando a conciencia por un acceso abierto a la información y al conocimiento, es evidente cómo uno de los retos de las revistas sobre libro antiguo será ofrecer acceso online a sus contenidos, tanto en el caso de las revistas modernas, como antiguas, con proyectos tan interesantes como el de Gazettes européennes du 18e siècle $e^{10}$.

Al igual que ahora, durante la Edad Moderna existían revistas que informaban de la actualidad del mundo de la librería, los libreros, sus agentes y autores. Seguramente la más importante, en proceso de estudio en la actualidad, sea el Journal de la librairie del inspector de la policía del libro parisino, Joseph d'Hémery ${ }^{11}$.

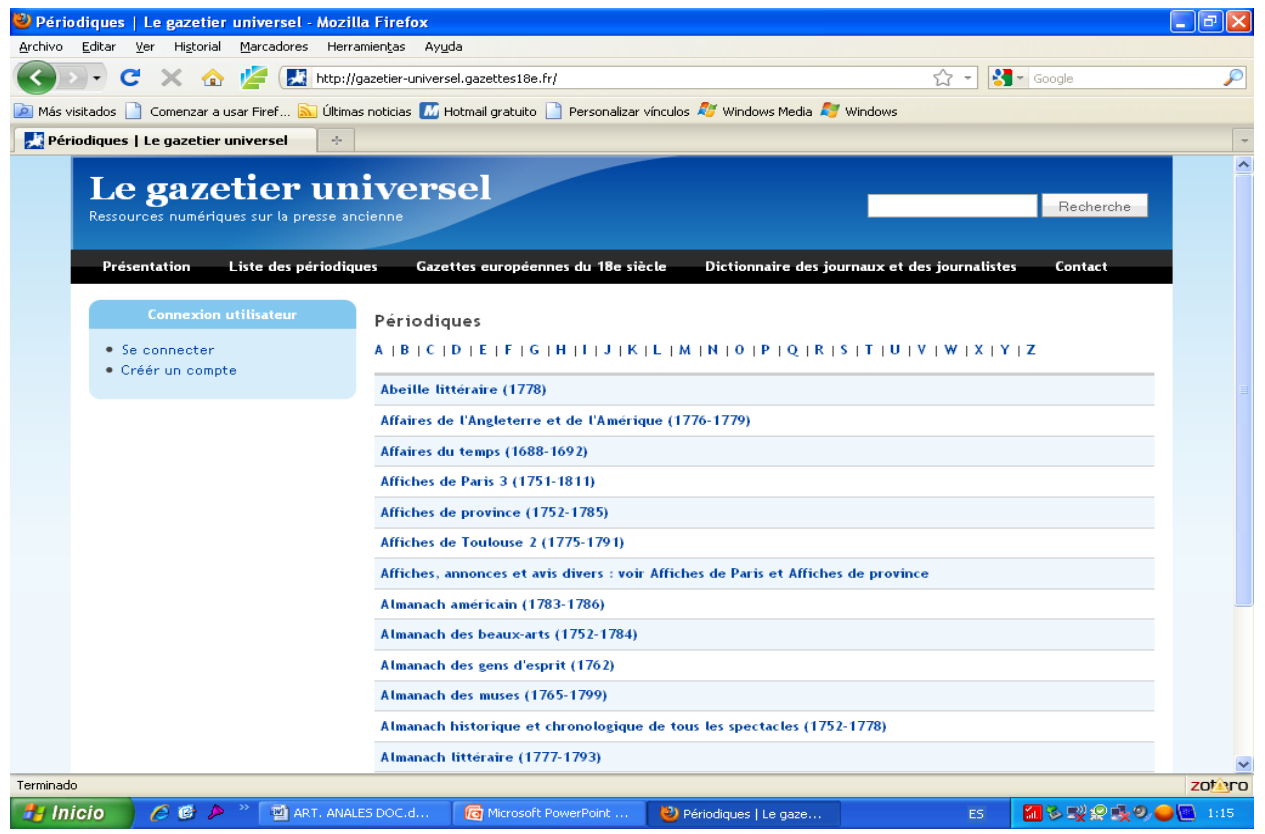

Figura 12. Gazettes européennes du 18e siècle.

El libro antiguo no ha sido ajeno al tirón y visibilidad de las redes sociales, razón por la que ha ampliado su presencia en éstas. Facebook y Twitter han abierto foros dedicados al libro antiguo, donde es posible discutir y debatir acerca de temas muy diversos. Una vez más constatamos como el interés extranjero por el libro antiguo es mayor que el español, cuyos foros apenas pasan de diez participantes. Lo cierto es que la Red 2.0 se configura como uno de los nichos profesionales más importantes para el libro antiguo. 


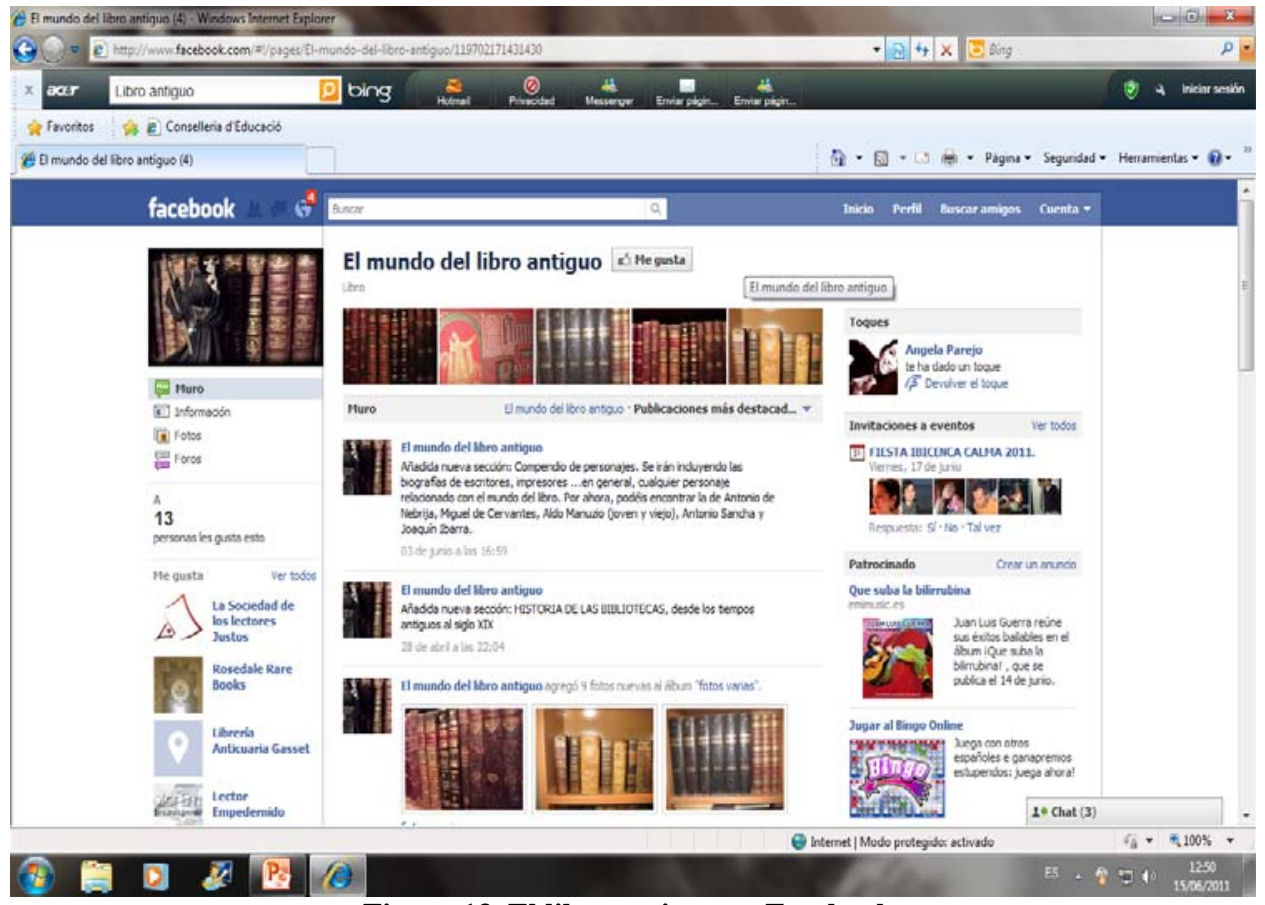

Figura 13. El libro antiguo en Facebook.

Pese a las innegables ventajas que aporta Internet al mundo del libro antiguo, es evidente que aún queda mucho por hacer, y que existen algunos hándicaps que con tiempo deberán corregirse para hacer del libro antiguo un producto atractivo en la Red. Entre ellas las más notables son:

- Hace falta homogeneizar portales y páginas web. Hay mucha disparidad y diversidad. A veces es como moverse por una selva de contenidos.

- Se debería potenciar el acceso abierto y público a la información y con ello al conocimiento frente a los intereses privados de las editoriales y los gastos excesivos de suscripción a algunas revistas.

- Sería necesario un portal bibliográfico actualizado sobre las investigaciones españolas y europeas en el campo de historia del libro y de las bibliotecas en la Edad Moderna. Una especie de ¿Quién es quién?

- Hay que continuar potenciando la digitalización de fondos antiguos en la Red, especialmente de materiales como las cartas, con criterios claros y rigurosos. En este sentido España creo que debe apostar aún más por estos proyectos, aún poco desarrollados.

- Sería muy útil también poner al servicio de los investigadores más herramientas de consulta online, tipo bibliografías, topobibliografías y tipobibliografías, entre otras fuentes. 
A raíz de lo dicho es evidente cómo el libro antiguo continúa siendo un objeto de atracción, al igual que lo fue para los curiosos e intelectuales de la Edad Moderna. Los medios para su difusión no han variado sustancialmente desde entonces sí los soportes, Internet, que han permitido, a diferencia de aquellos siglos, democratizar el acceso al libro antiguo. Entonces el reto continuaba siendo el mismo que ahora, organizar y conservar el saber. Para eso estaban los catálogos y las bibliotecas, a los que se une actualmente la digitalización. Una vez más, lo antiguo y lo nuevo conviven, con la convicción de que lo uno (digitalización) no existiría sin lo otro (libro antiguo). Una relación de amor-odio que jalona la historia moderna de Europa y la del presente siglo.

\section{CONCLUSIONES}

A modo de conclusión, me gustaría resumir muy brevemente los retos a los que deberá enfrentarse el mundo del libro antiguo en Internet. Ante todo, deberá prevalecer la calidad sobre la cantidad. La Red se ha de convertir en una buena herramienta referencial, pues los contenidos intrínsecos tendrán que seguir buscándose en los archivos y bibliotecas. Ello quiere decir, como la fórmula matemática, que menos por menos es más, es decir que hay que unificar frente a la diversidad. Uniformidad, exigencia de rigor, calidad y exhaustividad, son algunos de los desafíos que deberán acometer libreros, anticuarios, bibliófilos, profesores universitarios, subastas e instituciones para hacer del libro antiguo un producto atractivo, y cada vez más cercano en un mundo cada vez más digital.

Quisiera acabar uniéndome a las palabras de Jeanneney al afirmar que:

"En contra de lo que alguna vez soñaron los editores del siglo XIX, no puede haber una biblioteca universal, en este caso de libro antiguo. Como mucho, miradas específicas sobre lo universal. Por fuerza, siempre hay que elegir ${ }^{\text {"12 }}$.

El deseo es que la elección sea lo más acertada posible, de manera que tengamos disponibles en Internet herramientas rigurosas y actualizadas para poder acercarnos con una "mirada" a la historia de la edición. La otra mirada, las más cercana, nos la seguirá proporcionando como siempre la consulta a los archivos y bibliotecas que, pasados los siglos y las revoluciones tecnológicas, aún están ahí para continuar desvelando los enigmas de la historia del libro y de las bibliotecas durante la Edad Moderna.

\section{NOTAS}

1 DARNTON, R. Las razones del libro. Futuro, presente y pasado. Madrid: Trama, 2010, p. 14.

2 BAS MARTÍN, N. Documentación online sobre libro antiguo. Documentación de las Ciencias de la Información, 2007, vol. 30, p. 101-134.

3 Electronic Enlightenment. Disponible en: <http://www.e-enlightenment.com/>. [Consulta: 11 de julio de 2011].

${ }^{4}$ Voltaire Foundation. Disponible en: <http://www.voltaire.ox.ac.uk/www_vf/corres/corres_index.ssi> [Consulta: 11 de julio de 2011]. 
5 BAS MARTIN, N. De la circulation des livres et des idées entre l' Espagne et la France au XVIIIe siècle: Cavanilles et le libraire Fournier. En Journée d'Étude "Des livres entre l' Espagne et la France au siècle des Lumières”, celebrada en el Colegio de España en París el 12 de mayo de 2011. [En Prensa].

6 El Bibliófilo valenciano Luis Caruana mantiene un blog llamado Diego Mallén, Disponible en: $<$ http://diegomallen.blogspot.com/>. [Consulta: 11 de julio de 2011].

${ }^{7}$ Karlsruhe Virtual Catalog. Disponible en: <http://www.ubka.uni-karlsruhe.de/kvk_en.html>. [Consulta: 11 de julio de 2011].

${ }^{8}$ CHARTIER, R. Cultura escrita, literatura e historia. Conversaciones con Roger Chartier. México: FCE, 1999. p. 31-34.

9 Esprit des livres. Catalogues de vente de bibliothèques conservés dans les bibliothèques parisiennes. Disponible en: <http://elec.enc.sorbonne.fr/cataloguevente/>. [Consulta: 11 de julio de 2011].

10 Le Gazetier universal. Ressources numériques sur la presse ancienne. Disponible en: <http://gazetieruniversel.gazettes18e.fr/>. [Consulta: 11 de julio de 2011].

${ }^{11}$ Proyecto dirigido por la profesora Sabine Juratic y Jean-Pierre Vittu a través del ENS de París.

12 JEANNENEY, JN. Google desafía a Europa. El mito del conocimiento universal. Valencia: Universitat de València, 2007. p. 13.

\section{BIBLIOGRAFÍA}

BAS MARTÍN, N. Documentación online sobre libro antiguo. Documentación de las Ciencias de la Información, 2007, vol. 30, p. 101-134.

BAS MARTIN, N. De la circulation des livres et des idées entre l'Espagne et la France au XVIIIe siècle: Cavanilles et le libraire Fournier. En Journée d' Étude "Des livres entre l' Espagne et la France au siècle des Lumières”, celebrada en el Colegio de España en París el 12 de mayo de 2011. [En Prensa].

CHARTIER, R. Cultura escrita, literatura e historia. Conversaciones con Roger Chartier. México: FCE, 1999.

CLEMENTE SAN ROMÁN, Y. Bibliografías especializadas en la biblioteca histórica de la Universidad Complutense. Cuadernos de Trabajo UCM, 2009.

DARNTON, R. Accès public, contrôle privé. La Bibliothèque universelle, de Voltaire à Google. Le Monde Diplomatique, mars 2009.

DARNTON, R. Accès public, contrôle privé. 26.000 dollars l'abonnement. Le Monde Diplomatique, mars 2009.

DARNTON, R. Las razones del libro. Futuro, presente y pasado. Madrid: Trama, 2010.

DÍAZ-MAROTO, F.M. El mercado del libro antiguo en España visto por un bibliófilo. Madrid: Arco, 2009.

ECO, U. y CARRIÈRE, J.C. Nadie acabará con los libros. Madrid: Lumen, 2010.

FUMAROLI, M. La querelle des anciens et des modernes XVIIe-XVIIIe siècles, précédé de les abeilles et les araignées. Paris: Gallimard, 2001.

GUERRERO, T. Las anotaciones y comentarios de Darwin en sus libros, disponibles en Internet. El Mundo, 23 de junio de 2011.

HAZLITT, W. El espíritu de las obligaciones y otros ensayos. Barcelona: Alba, 1999.

JEANNENEY, J.N. Google desafía a Europa. El mito del conocimiento universal. Valencia: Universitat de València, 2007.

KELLY, S. La biblioteca de los libros perdidos. Barcelona: Paidós, 2007. 
McLUHAN, M. La Galaxia Gutenberg. Génesis del "Homo typographicus". Barcelona: Círculo de Lectores, 1993.

MÉNDEZ RODRÍGUEZ, E.M. La biblioteca digital como concepto. Realidad, utopía e índice de contemporaneidad. En Teoría y literatura artística en la sociedad digital: construcción y aplicabilidad de colecciones textuales informatizadas. Gijón: Trea, 2009.

REMÍREZ DE ESPARZA, F.A. El comercio del libro antiguo. Madrid: Arco, 2008.

RODRÍGUEZ RIVERO, M. Saber venderse. El País, 22 de junio de 2011.

STEINER, G. Los logócratas. Madrid: Siruela, 2006.

STEINER, G. Le silence des livres, suivi de Ce vice encore impuni. Paris: Arléa, 2006b.

TODOROV, T. El miedo a los bárbaros. Barcelona: Galaxia Gutenberg, 2008.

TODOROV, T. La memoria, ¿un remedio contra el mal? Barcelona: Arcadia, 2009.

Anales de Documentación, 2012, vol. 15, nº 1 